\title{
A CASA TIMORENSE E OS ESTUDANTES DO TIMOR-LESTE NO EXTERIOR.
}

\author{
THE TIMORESE HOUSE AND THE STUDENTS OF
}

TIMOR-LESTE ABROAD.

LA MAISON TIMORAISE ET LES ÉTUDIANTS DU TIMOR-LESTE À L'ÉTRANGER.

LA CASA TIMORENSE Y LOS ESTUDIANTES DE TIMOR ORIENTAL EN EL EXTERIOR.

Silvia Garcia Nogueira*
Renata Nogueira da Silva**

RESUMO: Este artigo é resultado do encontro de duas pesquisas etnográficas em andamento. Uma que versa sobre os timorenses em situação de estudo em universidades portuguesas e brasileiras sob a lógica da hospitalidade e outra sobre as noções de casas e casas sagradas em Timor-Leste e os modos como se articulam para dar sentido à dinâmicas de reprodução social. Este artigo pretende apresentar e discutir os significados culturais da casa timorense, assim como o modo como os estudantes no exterior concebem e constroem simbolicamente suas "casas", a do Timor-Leste e o local em que moram durante seus cursos superiores, além das conexões que estabelecem entre ambas. Para isso, realiza-se breves digressões sobre as relações entre os sentimentos de pertença e lugar dos estudantes, ligando a construção das suas próprias identidades à do Timor-Leste, em um processo de construção do nationness ("nacionidade") e do sentimento de sentir-se em casa (chez soi).

Palavras-chave: Casa; Timor-Leste; Estudantes timorenses; Família; Migrações Internacionais.

ABSTRACT: This article is the result of the meeting of two

\footnotetext{
* Doutora em Antropologia Social; Professora na Universidade Estadual da Paraíba (UEPB), João Pessoa, PB, Brasil; E-mail: snogueirari@gmail.com

** Mestre em Antropologia e doutoranda no Programa de Pós-graduação em Antropologia Social da Universidade de Brasília (UnB), Brasília, DF, Brasil; E-mail: rerenogueira@yahoo.com.br
} 
ethnographic researches in progress. One is about the Timorese in study in Portuguese and Brazilian universities under the logic of hospitality and the other on the notions of houses and sacred houses in East Timor and the ways in which they are articulated to give meaning to the dynamics of social reproduction. This article intends to present and discuss the cultural meanings of the Timorese house, as well as the way in which students abroad conceptually construct and construct their "houses", that of East Timor and the place where they live during their superior courses, besides the connections which they establish between them. To this end, brief digressions are made on the relations between students' feelings of belonging and place, linking the construction of their own identities with that of Timor-Leste, in a process of nation-building and the feeling of feel at home (chez-soi).

Keywords: Home; Timor-Leste; Timorese students; Family; International Migrations.

$\boldsymbol{R} \mathbf{E} \boldsymbol{S} \boldsymbol{U} \boldsymbol{M E}:$ Cet article est le résultat de la rencontre de deux recherches ethnographiques en cours. L'un concerne les Timorais en étude dans les universités portugaises et brésiliennes dans le cadre de la logique de l'hospitalité et l'autre sur les notions de maisons et de maisons sacrées au Timor oriental et la manière dont ils s'articulent pour donner un sens à la dynamique de la reproduction sociale. Cet article a pour but de présenter et de débattre des significations culturelles de la maison timoraise, ainsi que de la manière dont les étudiants à l'étranger construisent et construisent conceptuellement leurs "maisons", celles du Timor oriental et de leur lieu de cours supérieur qu'ils établissent entre eux. À cette fin, de brèves digressions sont faites sur les relations entre le sentiment d'appartenance et la place des étudiants, liant la construction de leur propre identité à celle du Timor-Leste, dans un processus de construction de la nation et de sentiment de chez soi.

Mots-clés: Maison; Timor-Leste; Étudiants timorais; Famille; Migrations Internationales.

RESUMEN: Este artículo es el resultado del encuentro de dos investigaciones etnográficas en curso. Una que se ocupa de los timorenses para estudiar la situación en las universidades portuguesas y brasileñas bajo la lógica de la hospitalidad y otra que dice respecto de las nociones de viviendas y casas sagradas en Timor Oriental y las formas cómo articulan para dar sentido a la dinámica de la reproducción social. Este artículo pretende presentar y discutir los significados culturales de la casa timorense, así como el modo como los estudiantes en el exterior conciben y construyen simbólicamente sus "casas", la de Timor Oriental y el lugar en que viven durante sus cur- 
sos superiores, además de las conexiones que establecen entre ambas. Para ello, se realizan breves digresiones sobre las relaciones entre los sentimientos de pertenencia y lugar de los estudiantes, vinculando la construcción de sus propias identidades a la de Timor Oriental, en un proceso de construcción del nationness ("nacionidad") y del sentimiento de "sentirse en casa" (chez-soi).

Palabras clave: Casa; Timor; Estudiantes timorenses; Familia; Migraciones Internacionales.

\section{INTRODUÇÃO}

Este artigo é resultado do encontro de duas pesquisas etnográficas em andamento. Uma delas versa sobre os timorenses em situação de estudo em universidades portuguesas e brasileiras sob o olhar do acolhimento, da hospitalidade e do bem-receber. A outra diz respeito às noções de casas e casas sagradas em Timor-Leste e os modos pelas quais são articuladas e acionadas para dar sentido às dinâmicas de reprodução social.

Em ambas, abordar o tema da casa e o repertório polissêmico a ela relacionado (família, amigos, lugar, ancestrais, objetos, país) possibilita compreender melhor as relações mantidas entre pessoas de diversas gerações, vivas e mortas. Permite, ainda, entender os processos de co-habitação (Viegas, Feijó, 2017; Cummings, 2015), ou seja, uma combinação de práticas, valores e crenças que reside principalmente na co-existência de instituições sociais baseadas simultaneamente no Estado e no costume.

A articulação entre os referentes marca, portanto, a singularidade cultural do próprio Timor-Leste, um país do sudeste asiático com uma grande recorrência de ocupações estrangeiras. Entre elas, a do período de colonização portuguesa (do século XVI até 1975), a ocupação japonesa durante a $2^{\mathrm{a}}$ Guerra Mundial (1942), a violenta ocupação indonésia (1975-1999), a intervenção direta e o acompanhamento da Organização das Nações Unidas (1999-2012).

Em 1999, mesmo após a "Ilha do Crocodilo" ter se tornado um país independente, violentos conflitos causados ainda por grupos pró -Indonésia exigiram a intervenção da ONU. Em decorrência disso, so- 
mente em 2002 a independência foi restaurada. Iniciou-se, então, um processo de construção de Estado e de construção de nação. De acordo com Leach (2012), a comunidade internacional estava mais preocupada com o primeiro no período pós-conflito do que com o segundo. $\mathrm{O}$ processo de state-building tem como foco o regime de governança, as instituições, o accountability e o estado de direito. $\mathrm{O}$ de nation-building se refere a um processo cultural que busca formar uma comunidade política coesa que seja capaz de sustentar o desenvolvimento de um estado funcional, colocando em relevo o desenvolvimento de comunidade, formação de identidade e integração nacional.

$\mathrm{Na}$ visão de Leach (2017), a identidade nacional timorense está sendo atualmente moldada por suas próprias mãos e os jovens desempenham um papel significativo nesse sentido, uma vez que a média de idade no país está em torno dos 18 anos. Estes, por sua vez, possuem suas concepções específicas sobre a identidade nacional timorense. Cabe dizer que eles são fluentes em Tétum, familiarizados com a língua indonésia e educados em Português - Timor-Leste tem como idiomas oficiais o Tétum e o Português, ainda que seja considerado um país multilinguistico (Goglia, Afonso, 2012).

Timor-Leste possui como um dos principais problemas a falta de infraestrutura (Butcher, Bastian, D’Arbon, Taouk, 2015). Criado em 2010, contendo objetivos e metas até 2030, o Plano Estratégico de Desenvolvimento do governo do ex-presidente Xanana Gusmão foi formulado para tirar o país da condição de ser um estado pobre do sudeste asiático. A realização de investimentos no campo da educação está dentro desse planejamento, que inclui a adoção de políticas voltadas para o estabelecimento de parcerias e protocolos de cooperação com instituições de ensino superior.

O movimento de saída do país de origem faz parte, portanto, de uma política do Timor-Leste voltada para a formação de quadros profissionais qualificados para atuação em seu recém-criado Estado. Independente dos lugares para os quais se dirigem, os estudantes que partem costumam manter os vínculos familiares e com amigos no/do Timor-Leste por meio das mídias sociais, como um recurso para trazer a "casa" para o local onde moram na situação da mobilidade estudantil. 
Diante desse quadro geral, este artigo pretende apresentar e discutir os significados culturais da casa timorense, assim como o modo como os estudantes no exterior concebem e constroem simbolicamente suas "casas"1 - do Timor-Leste e o local em que moram durante seus cursos superiores, além das conexões que estabelecem entre ambas. Ademais, serão ainda realizadas breves digressões sobre as relações entre os sentimentos de pertença e lugar dos estudantes, ligando a construção das suas próprias identidades à do Timor-Leste, em um processo de construção do nationness ("nacionidade") e do sentimento de sentir-se em casa (chez-soi).

\section{CASA E SUAS POTENCIALIDADES ANALÍTICAS}

O estudo antropológico das sociedades de casa tem uma vasta trajetória de debates teóricos e etnográficos. O conceito de casa (maison) como categoria analítica foi proposto por Lévi-Strauss (1986) para designar unidades de pertença e organização social que não podem ser definidas precisamente nem como famílias, nem como clãs, nem como linhagens. Portanto, a casa é concebida como um conceito mediador no qual o autor coloca em diálogo, por exemplo, estrutura e história; aliança e filiação. Lévi-Strauss define casa nos seguintes termos:

(...) pessoa moral detentora de um domínio, que se perpetua pela transmissão do seu nome, de sua fortuna e de seus títulos em linha real ou fictícia, considerada como legítima somente na condição de que essa continuidade possa se expressar na linguagem do parentesco ou da aliança e, na maioria dos casos, das duas em conjunto. (Lévi-Strauss, 1986, p.186)

1 Desde 2014, uma de nós vem desenvolvendo pesquisa sobre a centralidade da casa sagrada na organização social de muitas comunidades leste-timorenses. Outra de nós vem desenvolvendo pesquisa de campo junto a cerca de 30 estudantes timorenses em cursos de graduação e pós-graduação no Brasil desde 2013 e, entre 2017 e 2018, dentro de um pós-doutorado realizado no Instituto de Ciências Socais da Universidade de Lisboa, junto a aproximadamente 20 alunos de universidades portuguesas, em níveis de licenciatura e pós-graduação. 
Inspirados na noção lévi-straussiana de sociedade de casa, Carsten e Hugh-Jones (1995) apresentam considerações importantes sobre as possibilidades de enfoques nos estudos sobre casa e a relevância analítica dessa categoria. A proposta da obra é articular a noção de casa como uma forma específica de organização e expor sua utilidade em casos empíricos do Sudeste Asiático e da América do Sul. Os estudos de caso inseridos em contextos comparativos permitiriam ilustrar as relações entre edifícios, populações e categorias. Entre outras coisas, uma contribuição digna de nota dessa coletânea é a menção à transitoriedade das casas. Nessa perspectiva, a casa ganha o status de "entidade dinâmica", que compartilha o status de vivente com as pessoas que moram nelas, ocasionando o "processo de vida": morre, nasce, é destruída, renasce (Carsten, Hugh-Jones, 1995, p.37).

A centralidade da casa na organização social do sudeste asiático, em especial na Indonésia Oriental, área na qual Timor-Leste tem sido incluído, é apontada em diversas pesquisas. Fox (1993), por exemplo, no livro Inside Austronesian house relaciona o design interno de casas com as práticas sociais e rituais dos grupos específicos que nelas residem. Ele define casa como uma entidade física e como uma categoria cultural, que tem a capacidade de fornecer a continuidade social. Fox (1993) sublinha que a memória de uma sucessão de casas, ou de uma sucessão no interior de uma casa, pode ser um índice de eventos importantes do passado. Nessa perspectiva, a casa é também um repositório de objetos ancestrais que evidenciam uma continuidade com o passado.

A casa no Sudeste Asiático tem sido situada/apresentada nas etnografias articulada aos modos de organização social. A casa (doméstica) é também uma entidade de pertença e a casa sagrada (casa cerimonial) é uma edificação onde se realiza encontros relacionados aos eventos importantes do fluxo da vida e o culto dos ancestrais. A arquitetura, bem como a localização geográfica e os rituais relacionados às casas (domésticas e sagradas) podem determinar fronteiras, informar as práticas, orientar as relações no interior das famílias, dinamizar alianças, bem como guiar as políticas de distribuição de terras. Nesses termos, a casa é um princípio estrutural que nos permite 
compreender níveis e camadas de organizações sociais e políticas e complexos de referência morais.

Seguindo essa agenda de estudos, Waterson ${ }^{2}$ (2011), a partir de sua pesquisa entre os Toraja na Indonésia, indica que as relações entre casa e aldeia refletem o cosmos e, por isso, a arquitetura deve ser pensada para além de uma estrutura que cumpre a função de abrigar. É possível, inclusive, traçar a biografia das casas, dos objetos e das pessoas que as constroem e são construídas por meio delas.

De acordo com Waterson, os Toraja interagem constantemente com suas habitações como se fossem entidades vivas. A possibilidade de a casa sobreviver a cada membro humano que a habita é algo importante nas cosmologias indonésias e relaciona-se ao modo como as pessoas pensam o seu lugar no mundo. Assim, casa é recriada cotidianamente através das relações dos seres que nela habitam e os laços que ligam os antepassados e seus descendentes são renovados periodicamente por meio dos rituais. A condição essencial da existência da casa é a produção e reprodução simultânea da vida espiritual, econômica e social.

As discussões de Sparkes (2003) na introdução do livro The House in Southeat Asia e as reflexões de Kaene (1995) sobre casa, texto e objeto na Indonésia tornam algumas dimensões da discussão sobre as relações entre casa e arquitetura mais latentes. De acordo com Sparkes, por exemplo, as casas são marcadores de identidade étnica, balizam espaço, organizam as relações entre passado, presente e futuro e destacam as diferenças entre grupos. O autor destaca ainda que casas tanto podem dizer coisas para seus membros sobre categorias socioeconômicas e valores compartilhados pela comunidade quanto indicar aos estrangeiros o status de seus habitantes. Para Sparkes, as casas expressam categorias culturais e se diferenciam pelo estilo arquitetônico, tamanho e ornamento.

Keane (1995) descreve a casa tradicional (nesse caso a dos Sumbaneses na Indonésia) como o microcosmo, um emblema visual e símbolo da identidade local. A pretensão do autor é analisar os discursos sobre as práticas e a função da linguagem. A casa, nesses

2 Os comentários sobre Waterson são baseados na entrevista cedida a Alberto Goyena em 2011. 
termos, é tratada como objeto de discussão. Uma análise daquilo que se fala sobre as casas, da seleção dos discursos e sua performance associada às discussões orientadas pela busca de significados das casas e seus objetos pode ser uma boa estratégia de interpretação. As casas nessa parte do mundo não são concebidas somente como construções físicas que abrigam seus membros, mas também como uma categoria cultural por meio da qual vínculos são construídos e as gerações se perpetuam.

A partir desse cenário genérico da categoria casa na etnologia da Indonésia Oriental, apresentamos mais detalhadamente as uma lulik de Timor-Leste, traçando afinidades eletivas entre casas e casas sagradas, princípios de organização social, pertencimento e arquitetura.

\section{UMA LULIK DE TIMOR-LESTE}

As relações entre arquitetura, sistema de alianças e organização social povoam diversas pesquisas na região. Os registros de Cinatti, Almeida e Mendes (1987) no livro Arquitetura timorense apontam correspondências entre as concepções cosmológicas e religiosas na divisão do universo e o microcosmo residencial. Dissertam os autores:

na estrutura da habitação revela-se o simbolismo cósmico: a casa é a imagem do mundo, a sua cobertura é o Céu, o pilar ou poste principal é assimilado ao "eixo do mundo" que sustenta o imenso teto celeste e desempenha um papel ritual importante: é na sua base que têm lugar os sacrifícios em honra do ser supremo, Marômac [...]. Toda a construção e inauguração de uma moradia equivalem a um começo, a uma nova vida: para que a obra dure e "viva" deve ser animada, isto é, deve receber ao mesmo tempo uma vida e uma alma. A transferência da alma só é possível pela via de um sacrifício sangrento [...]. Todo o mundo exterior é tratado pelo timorense segundo o modelo apreendido nas relações com a sociedade, transferindo para as coisas vida, atos e emoções familiares na esfera das relações humanas (Cinatti, Almeida, Mendes, 1987, p.74). 
Similarmente à diversidade de tipos arquitetônicos residenciais, é possível encontrar mais de uma casa sagrada em cada povoação leste timorense (Sousa, 2007; Castro, Assis, 2010). Em algumas comunidades, as casas sagradas não diferem muito das casas de moradia, construídas a partir dos conhecimentos locais (casas adat), mas essas casas não são ocupadas, necessariamente, como moradias de seres humanos. Por oposição, destaca-se o exemplo das casas sagradas do grupo lingüístico Bunak, ${ }^{3}$ que precisam ser habitadas por seres humanos para contrabalancear a presença dos ancestrais. A falta de humanos demonstra que a família é desunida e desorganizada (Sousa, 2007).

Uma lulik simboliza a continuidade entre passado, presente e futuro. A recriação arquitetônica das habitações compreende um sentido sagrado e pode acionar diversas modalidades de relações e alianças: entre seres humanos, coisas, ancestrais, mortos etc. Trata-se de uma matriz de significados, que materializa conteúdos de diferentes ordens.

A esse respeito, Hicks (2004, p. 91-92) afirma:

[...] a building set aside for the storage of a descent group's sacred possessions, and it is that place more than any other where the interests of ghosts and kin most tangible converge. There material artefacts symbolizing the bonds that unite these two categories of kin are stored and public rituals of reciprocity by which ghosts and the descent group collectively satisfy each other's needs are carried out. [...] Ritual houses are said to have come down from ancient times, and I wast old they were built by the ancestors and contemporary kin are not empowered to build new ones. They were an emblem of a group's claim on the land they occupied, ownership derived from a mythical contract with the nature spirits that lived in the region.

As casas sagradas possuem disposições arquitetônicas particulares e sediam um conjunto de atividades do fluxo da vida. Esclarece Pena Castro (2010, p. 65):

3 De acordo com a Constituição (2002), as línguas oficiais de Timor Leste são a língua portuguesa e a língua tétum. $O$ inglês e o indonésio são considerados línguas de trabalho. Além das línguas já mencionadas, Timor-Leste possui, somadas ao tétum, 15 línguas nativas e dezenas de variantes. 
[...] as uma lulik timorenses fazem parte do conjunto de casas próprias da região austronésia. Do mesmo modo que as catedrais do período barroco não são um fenômeno exclusivo de um determinado país europeu, as uma lulik devem ser contempladas no seu contexto etnorregional. Partindo de uma particular disposição arquitetônica que reúne traves e postes, cobertura de erva e parede de bambu ou madeira, as casas representam neste contexto sociocultural os valores sociais e a formulação ideológica e moral das suas sociedades. São as casas que representam um grupo humano, relacionado por parentesco, pelo que se discrimina entre pessoas membros e pessoas alheias nas atividades e práticas desenvolvidas.

Uma das expressões mais recorrentes de identificação da nação leste-timorense nos discursos políticos e sociais é uma lulik - casa sagrada. Osório de Castro (1896, p.46-47) informa que uma lulik é

o templo dos 'objectos lúlic ${ }^{4}$ ' ou tabús da povoação, o seu Palácio. Cada família tem o seu 'uma-lúlic' doméstico ou familiar, em que os objetos lulic são guardados, se fazem oferendas de alimentos por ocasião das sementeiras e da colheita, e quando em casa há óbitos ou nascimentos.

Uma lulik é uma metonímia do mundo cósmico, expresso na aldeia e na casa de habitação. Com o propósito de manter o bem-estar das relações e da vida social, é preciso cumprir um conjunto de obrigações e prestar uma série de deferências relacionadas à casa sagrada. A esse respeito, Cinatti, Almeida e Mendes (1986, p.79) afirmam:

[...] habitada pelos espíritos dos antigos guerreiros, antepassados dos que habitam o povoado ou o reino. Construída por uma ou várias famílias é propriedade de toda a população e o elemento de união entre o clã: se a "uma lulic" desaparecer por ruína ou incêndio, grande desgraça abater-se-á sobre o povo e as famílias dispersar-se-ão. Quando de um incêndio ou má colheita os velhos e entendidos são consultados e geralmente a razão apontada é a incúria

4 Mantemos a grafia do texto pesquisado, por isso o uso de lulic. 
ou descuidos a que foi votada a casa; o remédio é repará-la quanto antes ou construir uma nova para que os espíritos dos avós não tenham de se queixar. A guarda da "uma lulic" é confiada a um velho ou velha do clã que são responsáveis por ela perante a população.

As pessoas que se reconhecem como partes da mesma casa sagrada são coagidas à colaboração, sobretudo nas ocasiões da (re) construção da casa sagrada ou da casa de um dos membros (Sousa, 2007). Nascimentos, casamentos, primeira colheita do arroz e do milho, Dia de Finados ${ }^{5}$ (2 de novembro), por exemplo, mobilizam pessoas, ancestrais e coisas em torno da casa sagrada.

Durante a invasão indonésia (1975), muitas casas sagradas foram destruídas ou atacadas. Nesse período, ora as populações fugiam, porque suas aldeias serviam como base aos combates entre o exército indonésio e as Forças Armadas de Libertação e Independência de Timor-Leste (FALINTIL), ora as pessoas eram deslocadas (pelos agentes indonésios) das regiões mais montanhosas, sendo a concentração em áreas baixas uma forma de impedir o apoio da população à guerrilha. Entretanto, Sousa (2007) destaca que as casas não só “permaneceram”, como continuaram a ser (re)construídas.

A casa sagrada tem sido acionada pelos veteranos de guerra como um dos elementos principais que contribuíram na vitória de Timor-Leste contra a invasão indonésia. Relatos dos mais velhos sugerem que, durante os 24 anos do conflito, ocorreram várias cerimônias em casas usadas provisoriamente como uma lulik e que elementos da natureza foram consagrados e entregues aos guerrilheiros como amuletos.

Para muitas populações em Timor-Leste, a casa sagrada encarna a presença dos antepassados. Cada comunidade é orientada por um conjunto de procedimentos definidos a partir dos vínculos das pessoas com os objetos, ancestrais e poderes lulik. Recorrentemente, esses protocolos são chamados de tradição, usos e costumes ou cultura. Dentro da casa sagrada, ou em função da mesma, as pessoas se comunicam com os antepassados. A sorte, o azar, o sucesso 5 O Dia de Finados era conhecido na Idade Média como "Dia de Todas as Almas". Essa data tem como objetivo reverenciar a memória dos mortos, dos entes queridos que já se foram, haja vista que, de acordo com a doutrina da Igreja Católica, a alma da maioria dos mortos está no purgatório passando por um processo de purificação. 
ou o fracasso na vida estão relacionados a dádivas, ou a castigos de Maromak (Deus) e dos antepassados que estão no outro mundo. Desse modo, cada atividade que constitui uma celebração é, da mesma forma, um agradecimento. Sua não realização pode ser considerada como uma traição aos antepassados (Correia, 2013).

Focando nas afinidades entre casa, casa sagrada e pertencimento, é possível dizer que uma lulik coloca em interação diversos domínios da vida. É a possibilidade de reconstituir laços e realimentar a memória coletiva de uma ou mais famílias. E, nesse caso, os rituais geram identificações materiais e imateriais, nas quais os seres humanos se reconhecem como parte de uma família, casa ou casa sagrada.

\section{A CASA NA ÓTICA DOS ESTUDANTES TIMORENSES NO EXTERIOR}

A complexidade cultural, os vínculos que engendra e os significados singulares que carrega fazem da casa uma importante referência para a compreensão de uma série de eventos e domínios da vida social timorense, como visto. Diante disso, dentro de um contexto migratório, uma pergunta enganadoramente simples como “onde é sua casa?” coloca em jogo as relações que, no caso em tela, os estudantes timorenses no exterior mantêm com o próprio Timor -Leste e a sua nova vida em outro país.

A despeito da diversidade conceitual e da própria construção social cotidiana da casa habitada, como "lugar de repouso, produção de alimentos, relações parentais" (Brum, 2014, p.18), os alunos fora do país deparam-se com uma questão sempre presente para a maioria deles: como estar (português, brasileiro, australiano, indonésio, inglês, países destino para uma grande parte dos que estudam fora do Timor-Leste) sem deixar de ser timorense? Ou, na fala enfática de um dos interlocutores da pesquisa, um jovem no terceiro ano de Direito em Portugal, "estou aqui mas não posso me esquecer quem eu sou”. O sentimento de ser de um lugar e estar em outro é acionado recorrentemente em Timor-Leste para dar sentido às experiências de migração interna, muitas vezes sintentizadas na oposição (cidade- 
montanha). "Vivo em Díli, mas sou de Same" (Manufahi), afirmava recorrentemente uma interlocutora de pesquisa, estudante e funcionária da Universidade Timor Lorasa'e (UNTL).

Nesse sentido, as casas desses estudantes nos locais de destino - quartos em alojamentos universitários, casas e apartamentos compartilhados com outros membros da família que migraram antes, simultaneamente ou depois, locais compartilhados com outros estudantes timorenses - representam, como já observado por Brum (2014, p.167) sobre a Maison Du Brésil, a casa de estudantes brasileiros no exterior em várias partes da Europa,

[...]lugares de habitação temporária que passam a se constituir, pela atuação dos diversos sujeitos que a freqüentam, em territórios educacionais limítrofes de produção cultural e de sua transformação. Estas territorializações se processam a partir da territorialização com relação ao Brasil e reterritorialização na Europa, envolvendo desejos de uma formação educacional cosmopolita no exterior, mas que por suas características de inserção habitacional remete à comunicação com o local, conforme analisa Hannerz (1990, p.253)

Ainda conforme observado pela autora, as territorializações ocorrem de diversos modos, como "a disposição dos móveis nos quartos dos residentes, no uso de imagens que remetem aos familiares e amigos deixados" (p.167).

Em geral, a casa dos estudantes no local de estudo é composta de mobiliário local (muitas vezes padrão, já que alugam o lugar mobiliado), mas com objetos provenientes do Timor-Leste e da família. Tecidos identificados com região de origem familiar (tais, utilizados em ocasiões especiais, e salendangs, ofertadas como forma de boas-vindas ou reconhecimento aos estrangeiros que as recebem), a bandeira do Timor-Leste e roupas reproduzindo essa bandeira, além de outros objetos que representam vivos e mortos dentro de seu grupo de origem.

$\mathrm{O}$ tema da casa recorrentemente volta de algum modo em conversas informais com os interlocutores. Justamente por isto e a partir dessas menções, quatro perguntas foram apresentadas a dez 
estudantes $^{6}$, em Portugal (4), no Brasil (5) e na Austrália (1), presencialmente ou por meio de alguma mídia social: 1- Onde é a sua casa?; 2- O que é casa para você?; 3- Que relação mantém com sua casa no Timor e no lugar onde mora?; 4- Como é a sua casa no local onde estuda ou estudou e que elementos do Timor existem nela?

No que tange à primeira pergunta, "Onde é sua casa?", a maioria fez referência ao seu distrito e a seu país. "A minha casa fica situada em Venilale, Baucau, Timor Leste", "a minha casa em Timor localiza-se em Município de Lautém/sub administrativo Luro/ Bairro ou Suco Baricafa", "a minha casa fica em Dili [capital]" ou simplesmente "Timor" são algumas das respostas que indicam o lugar que consideram sua casa. Somente um estudante ouvido, que muito recentemente havia voltado ao Timor, fez referência ao local onde estudava e a outros em que considerou que eram também uma "casa": "A minha casa é em Dili, neste momento, lol [sinal gráfico, na mensagem do estudante, indicando comemoração]. Já tive oportunidade de viver e ter casa em Lisboa ou fora de Timor".

As conexões entre lugar e pertença vêm sendo discutidas por vários autores no campo das migrações internacionais. Marandola Jr. e Gallo (2010, p.410), por exemplo, discutem a relação "self-lugar" como uma "teia indissociável de mútua constituição", em que ocorre um embate entre fenômenos e dinâmicas de processos sociais em uma "realidade geográfica". Para os autores:

O processo de desenraizamento original iniciado pelo movimento migratório se dá, em termos existenciais, pela alteração da territorialidade consolidada, a modificação desta relação originária self-lugar, saindo do lugar-natal, o que implica deixar os lugares de infância, juventude ou idade adulta, responsáveis pela nossa formação enquanto pessoa e sobre os quais está edificada nossa identidade. Implica, portanto, sair dos territórios de segurança e lançar-se no mundo. (Marandola Jr. e Gallo, 2010, p.410)

6 Agradecemos a Adolfino Varela, estudante timorense no Brasil, o contato com outros alunos timorenses. Alguns para os quais uma de nós enviou perguntas via mídia social (email, whatsapp) não eram conhecidos pessoalmente, ainda que a maioria sim e uma parte tenha sido abordada a partir de contato direto. Cerca de cinco estudantes para os quais foram enviadas não responderam. Entretanto, aqui são utilizadas como fontes dados obtidos na observação e convívio com os estudantes timorenses, em Portugal e no Brasil. 
Desse modo, vão sendo tecidos elos entre o que se leva no processo migratório do lugar-natal e o que se encontra no lugar de chegada, através do que os autores também apontam: "percepção, sensação, cognição, representação e imaginação" (p.411), mas também, referente ao universo social da pesquisa, emoções e sentimentos relacionados a ambos, a uma vida anterior e atual, antes, durante e depois da mobilidade estudantil. Conforme Marandola Jr. e Gallo (2010, p.412), "o migrante precisa reconstruir sua casa ao mesmo tempo que reconstitui a si mesmo".

A segunda pergunta - "O que é casa para você?" - provocou respostas nessa direção do self-lugar. Os estudantes relacionam casa e lar, reforçando o entendimento de que o conceito de casa carrega muito mais do que a concepção de um espaço físico, de acordo com os depoimentos de alguns estudantes abaixo:

[...] a casa é um lar!

[...] uma casa para mim é um lar, onde se vivem e convivem pessoas com alguma proximidade ou relação, que pode ser de família ou não, direta ou indiretamente. É um local especial, onde nós passamos a maior parte do nosso tempo ou dia a dia, com pessoas que nós amamos.

[...] a Casa pra mim é um lugar onde a minha alma fica embora eu esteja fora nela. É um lar onde eu me sinto muito seguro e abraçado por ela, principalmente o meu quarto.

[...] Casa para mim é como uma proteção, eu sinto mais segura, sinto amor e carinho dentro dela porque existe uma família que eu amo muito.

[...] Como estudante num lugar tão distante da minha casa. Esta casa que estou morando mantém o seu funcionamento como meu lugar mais confortável e seguro para eu continuar a minha vida durante alguns anos, principalmente a vida acadêmica. 
Nesse sentido também, tal como o faz Bauman (2005), o mundo é percebido como o espaço social por excelência da insegurança, ao contrário da casa. Entre os estudantes, de modo singular, a proteção e o conforto também podem aparecer sob metáfora, conforme palavras do aluno na Austrália: "a casa é um lugar ou edifício que dá a sombra para as pessoas viverem".

A relação entre lugar-natal, sentimento de pertença e o mundo foi levantada também por outro aluno no Brasil. Para ele,

[...] a CASA [letras maiúsculas na mensagem original] é um lugar onde tudo começou, significa o lugar onde comecei a conhecer o mundo, onde cresci, onde comecei a sonhar pra conquistar o meu mundo e onde eu sinto-me confortável de todos os outros lugares.

A noção de um lugar de partida, "onde tudo começou" para o mundo e o "meu mundo" - denotando as articulações entre mundo interior e exterior, self e lugar -, enfatizam o movimento, algo típico daqueles que estão em situação de mobilidade. Especificamente no contexto migratório, para Torresan (2004, p.45) "a ideia de casa pode ser adquirida em e através do movimento" (tradução minha), ainda que, tal como interpretado por Frangella (2014, p.90), “casa [...] pode significar o lugar material e simbólico, constituído por familiares que ali [país de origem] foram deixados, e para o qual se deseja voltar". Entretanto, como essa autora ressalta, o "tempo de estado no circuito migratório também pode mudar as projeções em torno da casa para a sociedade de destino" (Frangella, 2014, p.87).

As pontes estabelecidas entre os lugares de partida e destino tendo como referenciais a casa dos estudantes no Timor-Leste e onde estudam no exterior ficam mais evidentes por meio das respostas à pergunta "Que relação mantém com sua casa no Timor e no lugar onde mora?". A ela, um dos interlocutores respondeu do seguinte modo:

[...] A relação com minha casa é fantástica! Me sinto em casa quando fico sozinha no meu apartamento aqui no Brasil. No Timor, tenho uma relação muito forte com minha casa, o seu cheiro, a tagarela da 
mamãe, as piadas dos irmãos, a cozinha tradicional de lenhas, os pés de mangas rodeadas, entre outros, esses são elementos essenciais que mantêm a minha relação com ela.

O relato desse aluno no Brasil remete a uma relação entre o apartamento (a casa/lar no Brasil) e a casa no Timor construída tanto pelo imaginário, pelas lembranças e pelas saudades do que ficou para trás quanto pela possibilidade de acessar a esse universo, mesmo que parcialmente, por meio da comunicação com a família via redes sociais. Não à toa o uso do Facebook e do Whatsapp ${ }^{7}$ são recursos muito utilizados no estabelecimento dessas conexões entre uma (a casa no Timor) e o apartamento (no Brasil).

A experiência de um estudante que retornou em 2018 ao Timor, contudo, remonta a uma parcela de timorenses em Portugal que possuem outros parentes que lá vivem ou viveram, seja devido à formação universitária no país ou a outros motivos que os levaram a migrar (como a busca de trabalho). Em certa medida, eles se percebem como familiarizados com o estilo de vida português.

A relação que estabelecem com a casa habitada por outros membros da família ou amigos timorenses, de algum modo, parece fortalecer a ideia de proximidade com a casa deles no Timor-Leste, fazendo-os sentirem-se em casa (chez-soi), ainda que a nova casa não seja depositária de "memória, história, até sentimentos":

[...]Vou responder como se eu estivesse a viver ou morar em Lisboa. No lugar onde eu morava é quase igual à minha casa em Timor. Vivia com a minha família (irmãos, tia, prima, sobrinha, etc). Tudo que se passava em Timor, recebíamos sempre notícias e informações de familiares ou parentes. Acompanhávamos tudo.

Em Timor, só estavam os meus pais, todos nós estávamos fora de Timor. Às vezes pensamos que a distância dificulta tudo, mas não. Temos sempre maneira de criar pontes e contactos com pessoas do outro lado. A minha relação com a minha casa em Timor é que tinha tanta memória, história, até sentimento. A convivência que não é igual a todo lado

7 Para uma discussão baseada em uma pesquisa empírica de fôlego sobre os usos por jovens das redes sociais, ver Miller e Sinanan (2017) e Miller et al. (2016).

8 Uma aluna no Brasil diz que a relação que mantèm com sua casa é de "amor e carinho", reforçando a dimensão afetiva da casa e com os que lá habitam. 
do mundo. Em Lisboa é diferente! Acho que podem ser as mesmas pessoas a viver numa casa em Lisboa e em Timor, mas é completamente diferente dum lugar ao outro. Assim, também nos faz pensar que uma casa não é só lugar de viver e conviver. É mais do que isso. Porque as circunstâncias que rodeiam são diferentes. As condições socioculturais são diferentes, etc.

Contudo, posso dizer que tinha uma boa relação e proximidade com as duas casas, em Lisboa e em Timor.

Bauman (2005, p.20), porém, possui uma leitura particular a esse respeito: "Pode-se até começar a sentir-se chez-soi, 'em casa', em qualquer lugar - mas o preço a ser pago é a aceitação de que em lugar algum se vai estar total e plenamente em casa”. Esta percepção apontada pelo autor é compartilhada por uma população migrante significativa, incluindo-se os estudantes timorenses que sentem isso especialmente no retorno ao Timor-Leste, após a formação no exterior.

Os interlocutores da pesquisa lidam com o que incorporam de uma e outra cultura, no país de destino ou no retorno ao país de origem de modos distintos. Assim, se por um lado um aluno contou que quando está na casa dos avós procura se adequar de modo respeitoso ao que eles consideram correto (falar a língua corrente na família, conversar sobre temas correntes locais, etc.), por outro lado uma aluna, em uma conversa informal, contou que os alunos que retornam são identificados por seus modos de andar, vestir e falar, muitas vezes gerando uma percepção local de arrogância diante dos que ficaram em Timor-Leste.

A preocupação com a manutenção e preservação do que seria a "alma" timorense, a "alma" da casa - enquanto forma de organização social - e os usos e costumes que ajudam a defini-la coloca para alguns dos estudantes a questão sobre onde escolhem viver suas vidas depois da capacitação profissional fora do Timor-Leste. Sujeitos a outros valores, práticas sociais, ritmos de vida, códigos culturais e padrões de interação, que a experiência migratória traz, alguns deles demonstram dúvidas sobre o que farão e para onde irão depois de terminarem suas formações. As chances de emprego e as condições de trabalho são colocadas em questão no momento de tomada de decisão sobre como proceder. 
As relações que mantêm com a casa no Timor-Leste, o estilo de vida experimentado onde estudam e a adesão (ou não) a um futuro imaginado (sonhado) eventualmente diverso no que se refere às tradições timorenses os levam, principalmente aos estudantes mais jovens, a terem um sentimento de dúvida para com a decisão que terão que tomar. Nesse sentido, a relação que mantêm com a uma no Timor-Leste durante a experiência de estudar fora influencia o cotidiano desses estudantes, assim como seus desejos para o futuro e o modo como se inserem socialmente.

Não migram apenas pessoas. Estão em trânsito objetos, pessoas e crenças. Nesta migração ocorre de certa forma uma recomposição de uma ideia compartilhada de casa. No caso timorense os objetos que remetem aos avós, aos municípios e à nação compõem um baú de relíquias que poderá ser expandido de acordo com as marcas emocionais dos trânsitos. Uma parte da literatura sobre casa, como visto, indica que ela pode ser pensada como um repositório de objetos ancestrais que evidenciam uma continuidade com o passado.

Essa visão é boa para refletirmos sobre os processos através dos quais a continuidade é performada em tempos e espaços distintos de Timor-Leste. Os objetos levados de Timor-Leste para a nova casa, onde os estudantes residem no país de destino, por exemplo, indicam formas de estabelecer vínculos com o passado no tempo presente. Desse modo, diante da quarta pergunta - "Como é a sua casa no local onde estuda ou estudou e que elementos do Timor existem nela?" -, os elementos materiais e imateriais referidos levados na mudança para a nova habitação funcionam como dispositivos de conexão identitária.

Algumas das respostas possuem elementos comuns, em especial no que se refere aos objetos timorenses que os conectam à casa, ao lar, ao próprio Timor-Leste. A bandeira do país, tais provenientes dos distritos de pertença da família, algum tempero específico (p.ex. piri-piri) e músicas timorenses (muito referidas por eles) são alguns dos elementos presentes que conferem a sensação de segurança e familiaridade, possibilitando transformar o espaço arquitetônico da experiência migratória em um lar, ainda que provisório: 
[...] A casa ou quitinete onde eu moro, lembra um pouco da minha casa com a bandeira pendurada no meu quarto. A estrutura é muito moderna, mas com o tempo eu me associo e me sinto familiarizado. É um lugar bonito. Quando escuto músicas timorenses me sinto em casa. A bandeira, os dois tais oferecidos pela minha mãe e as musicas timorenses são elementos que me mantém conectado com o Timor.

[...] Estou consciente que no momento estou vivendo longe da minha família, então a questão de segurança é altamente importante depois da questão saúde e é isso que minha mãe sempre me diz. Estou querendo dizer que moro num lugar seguro, num condomínio, meu apartamento tem três quartos, dois banheiros, uma cozinha, uma sala de visita e uma área de serviço. Ou seja, estou compartilhando com alguns amigos meus.

Os elementos do Timor que existe nela são: a bandeira, as músicas do meu país que muitas vezes fico escutando, isso me faz com que sinta-me em casa.

[...] Em Lisboa, a minha casa tem uma parte de decoração timorense, com estátuas e panos de Timor, tais e uma lulik, bandeira nacional de Timor, e até piri-piri [pimenta] de Timor.

[...] Moro num prédio lindo, existem vários elementos principalmente a língua Tetum, conversamos todos os dias, os tecidos do Timor, tais, selendang, e mortel (colar).

A conexão estabelecida por meio de costumes timorenses reproduzidos na nova casa (comer determinados alimentos, ouvir músicas ouvidas no Timor-Leste, conversar em Tetum, usar acessórios e roupas do país de origem) e ter presente a bandeira como símbolo da terra-natal (estimulando um sentimento de nationness ou "nacionidade"), combinados à comunicação regular com a família e amigos timorenses por meio de mídias sociais, representam a possibilidade de levar parte da sua casa original à nova casa, não se esquecendo quem se era e de onde se veio. 
Nesse caso, lembrando o que diz Raynor (2015) quanto às narrativas sobre a migração, estas expõem muitas vezes a artificialidade das fronteiras espaciais, uma vez que são geradas a partir de processos de negociação e apropriação cultural. Assim, ao se conceber a casa na situação da mobilidade estudantil como um espaço composto por "vida e alma" (Cinatti, Almeida, Mendes, 1987), preenchido por objetos, ideias, medos, crenças, hábitos, etc., que ajudam a construir a familiaridade com a casa original, é possível perceber o que Marc Augé (1994) chama de "íntima união entre o espaço e o pertencimento", em cruzamentos das dimensões nacional e transnacional, global e local na vida contemporânea.

A presença constante da bandeira do Timor-Leste na casa dos estudantes no exterior expressa um sentimento e um referencial de pertencimento nos dois níveis apontados por Verdery (2000, p.242): no sentimento do "eu" do indivíduo como nacional e na identidade do todo coletivo em relação aos outros da mesma espécie. Tendo em vista os processos de state-building e nation-building pelos quais passa o país, as negociações culturais que ocorrem no espaço da casa do estudante no exterior de algum modo reproduzem a própria singularidade timorense baseada na coexistência de referentes tradicionais e modernos, que marca a co-habitação.

Entre costumes novos e antigos, objetos familiares trazidos na mobilidade e outros recém-adquiridos no novo local de moradia, vão sendo tecidas as interpretações próprias à maioria dos jovens estudantes no exterior sobre quem são, quem é o Timor-Leste e as relações vivenciadas na experiência migratória que compõem o self-lugar. De acordo com Verdery (2000, p.239-240), a "nação [...] é um aspecto da ordem política e simbólica-ideológica, bem como do mundo da interação e dos afetos sociais". Por isto mesmo, problematiza a seguinte questão: "como se desenvolve o sentimento do 'eu' como nacional?” (p.242).

Para a autora, que relaciona a pergunta ao problema das subjetividades nacionais - "no plural, pois não podemos presumir que haja apenas uma forma de nos experimentarmos como nacionais" (Verdery, 2000, 242) -, ocorreria uma diferença entre nacionalis- 
mo e nacionidade (nationness). O primeiro termo, entendido como relacionados aos sentimentos conscientes que tomam a nação como um objeto de devoção ativa; o segundo, às interações e práticas cotidianas que produzem um sentimento intrínseco, frequentemente não articulado de pertencer, de estar em casa. É a este último (nationness) que as conexões estabelecidas entre a casa no exterior e a do Timor-Leste parecem referir-se.

\section{CONSIDERAÇÕES FINAIS}

Este artigo buscou apresentar e discutir a casa (uma) no e do Timor-Leste em múltiplas dimensões. Optou-se por fazer isso privilegiando o ponto de vista de alguns estudantes timorenses no exterior, que se deparam com o desafio de terem que constituir um espaço de habitação com o qual se identifiquem.

A construção simbólica da casa timorense nessa nova moradia abrange a manutenção dos vínculos familiares e com amigos no/ do Timor-Leste por meio das mídias sociais, objetos trazidos do país e costumes (novos e tradicionais) praticados no lugar de destino. Trata-se de um recurso para trazer a "casa" da terra-natal para o local onde moram na situação da mobilidade estudantil, em que vão sendo tecidas as relações self-lugar (combinação do mundo interior com o exterior) e os sentimentos de nationness, de chez-soi.

A casa para os estudantes é entendida como um espaço de segurança, de afetos, de identidade, de interações sociais com a família. Remete, ainda, à dimensão sagrada da uma lulic e revela as relações entre arquitetura, sistema de alianças e organização social. Por meio dela os vínculos são construídos e as gerações se perpetuam.

Tendo em vista que a média da população timorense gira em torno dos 18 anos, que os jovens desempenham papel fundamental nos processos de construção de nação e de estado e que a trajetória de ocupações externas é uma marca do país, o vínculo entre as casas no exterior e no Timor-Leste, em alguma medida, parecem carregar simbolicamente aquele traço cultural particular, que é a coexistência de referenciais tradicionais, baseados no costume, e modernos, 
baseados no Estado, sob forma de co-habitação. Nesse sentido, as relações mantidas com a uma e a uma lulik podem vir a representar o modo como planejam definir os destinos do Timor-Leste por suas próprias mãos. Somente assim, onde quer que estejam, poderão sentir-se em casa.

\section{REFERÊNCIAS}

AUGÉ, M. Pour une anthropologie des mondes contemporains. Paris: Aubier, 1994.

BAUMAN, Z. Identidade. Rio de Janeiro: Jorge Zahar Ed., 2005.

BLACKWOOD, E. Webs of power: women, kin and community in a Sumatra village. Cumnor Hil: Rowman \& Littlefield, 2000.

BRUM, C. K.. Maison du Brésil: um território brasileiro em Paris. Porto Alegre: Editora Evangraf, 2014.

BOURDIEU, P. Poder simbólico. Lisboa: Difel, 1989.

BOVENSIEPEN, J. M. Lulik: taboo, animism or transgressive sacred? An exploration of identity, morality and power in Timor-Leste. Oceania, v. 84, nº. 2, pp. 121-137, 2014.

CARNEIRO, E. Candomblés da Bahia. Salvador: Progresso, 2008.

CARSTEN, J.; HUGH-JONES, S. (Eds.). About the house: Lévi-Strauss and Beyond. Cambridge: Cambridge University Press, 1995.

CASTRO, L. A. G.; ASSIS, C. (Orgs.). Património cultural de Timor-Leste: as uma lulik do distrito de Ainaro. Ferrol: Secretaria de Estado da Cultura da República Democrática de Timor-Leste, 2010.

CINATTI, R.; ALMEIDA, L.; MENDES, S. Arquitectura timorense. Lisboa: Instituto de Investigação Científica Tropical - Museu de Etnologia, 1987.

CORREIA, J. Construção de casas sagradas (uma lulik) na sociedade timorense: uma perspectiva sobre o desenvolvimento e o turismo comunitário no distrito de Baucau. 2013. Dissertação (Mestrado em Sociologia), Universidade do Minho, Portugal.

FIDALGO CASTRO, A. Objetos incómodos: el lugar de las "uma-lulik" en el EstadoNación de Timor-Leste. Cadernos de Arte e Antropologia, v. 4, no. 1, pp. 65-84, 2015. Disponível em: <http://cadernosaa. revues.org/849>. Acesso em: 11 mar. 2017.

FOX, J. (Ed.). Inside Austronesian houses: perspectives ondomestic designs for living. Camberra: ANU, 1993.

FRANGELLA, S. O tênue equilíbrio no movimento: a vicinalidade na 
migração transnacional. Revista de Antropologia, v.57, nº.1, 2014. Disponível em: http://www.revistas.usp.br/ra/article/view/89109. Acesso em: 30 de setembro de 2017. DOI: 10.11606/2179-0892. ra.2014.89109

GÁRATE CASTRO, L. A. As uma lulik e o contexto da sua localização no espaço. In: Património cultural de Timor-Leste. as uma lulik do distrito de Ainaro. Ferrol: Secretaría de Estado da Cultura da República Democrática de Timor-Leste, 2010.

GOGLIA, F., AFONSO, S.. Multilingualism and language maintenance in the East Timorese Diaspora in Portugal. Ellipsis. Journal of the American Portuguese Studies Association, nº.10, pp. 73-99, 2012.

GOYENA, A. O fascínio ocidental pelo original: entrevista com Roxana Waterson. Enfoques - Revista dos Alunos do PPGSA-UFRJ, v. 12, no. 1, pp. 142-151, 2013. Disponível em: <http://issuu.com/ revistaenfoquesufrj/docs/vol12_1>. Acesso em: 15 maio 2016.

HICKS, David. Tetum ghosts and kin: fertility and gender in East Timor. 2 ed. Illinois: Waveland, 2004.

KEANE, Webb. The Spoken House: Text, Act and Object in Eastern Indonesia. American Ethnologist, v.22, n' .1 , pp.102-124, 1995.

LEACH, M. Nation-Building and National Identity in Timor-Leste. Londres: Routledge, 2017.

LÉVI-STRAUSS, C. A noção de casa. In: Minhas palavras. São Paulo: Brasiliense, 1986.

MARANDOLA JR., E.,GALLO, P.M.D.. Ser migrante: implicações territoriais existenciais da migração. Rev. Bras. de Estudos Populacionais, v. 27, n'.2, pp.407-424, 2010.

MILlER, D., SINANAN, J.. Visualising Facebook. A Comparative Perspective. London: UCL Press, 2017.

MILLER, D. et al. How the World Changed Social Media. London: UCL Press, 2016.

OSÓRIO DE CASTRO. A Ilha Verde e Vermelha de Timor, Lisboa, Fundação: Oriente/Livros Cotovia, 1986.

PENA CASTRO, M. J. Os agrupamentos ou conjuntos de uma lulik. In: CASTRO, L. A. G.; ASSÍS, C (Eds.). Património cultural de TimorLeste: as uma lulik do distrito de Ainaro. Ferrol: Secretaria de Estado da Cultura da República Democrática de Timor Leste, 2010, pp. 125-135.

RAYNOR, C.. Linguagem, espaço e nação: um mapeamento das identidades multigeográficas do protagonista imigrante. Estudos de Literatura Brasileira Contemporânea, no. 45, pp. 159-182, jan./jun., 2015. 
SOUSA, L. M. G. As casas e o mundo: identidade local e Nação no patrimônio material/imaterial de Timor-Leste. Etnografia. In: CONGRESSO INTERNACIONAL, III, 13-14 jul. 2007. Cabeceiras de Basto. Actas..., 2007.

SPARKES, S. Introduction: the changing domain of the house in Southeast Asia. In: SPARKES, S.; HOWELL, S. (Eds). The House in Southeast Asia, 2003.

TORRESAN, A. M. S. Loud and Proud. Immigration and identity in a brazilian portuguese post colonial encounter in Lisbon, Portugal. 2004. Thesis (Doctoral) University of Manchester.

VERDERY, K. “Para onde Vão 'Nação' e 'Nacionalismo'?” In: BALAKRISHNAN, G. (Ed.). Um Mapa da Questão Nacional. Rio de Janeiro: Contraponto, 2000. pp. 239-247.

VIEGAS, S.M., FEIJÓ, R.G. (Eds.). Transformations in independent TimorLeste. Dynamics of social and cultural cohabitations. Londres, Routledge, 2017.

WATERSON, Roxana. Houses and the built environment in Island SouthEast Asia: tracing some shared themes in the uses of space. In: FOX, J. (Ed.). Inside Austronesian houses: perspectives on domestic designs for living. Camberra: ANU, 1993. pp. 227-243. 